\title{
NA SALA DA EXECUÇÃO - O ÚLTIMO ATO DO DRAMA DOS EXPLORADORES DE CAVERNAS?
}

\author{
VOLTAIRE DE FreitAS MICHEL ${ }^{1}$ \\ MARC ANTONi DEITOS 2
}

\begin{abstract}
RESUMO: O artigo apresenta uma fantasia especulativa, a partir do problema filosófico proposto por Lon L. Fuller, em 1949, em sua obra $O$ caso dos exploradores de cavernas. Desde o fato narrado pelo autor, a morte de um dos exploradores por seus companheiros presos numa caverna, o texto original retrata a simulação de um julgamento num cenário distópico e futuro, no ano de 4300, no hipotético país Newgarth. Nesse trabalho, a proposta é prosseguir com a discussão, colocando a decisão sobre a efetiva condenação dos exploradores nas mãos e mentes dos seus carrascos - os personagens fictícios Tomás, Helmut e Ronaldo. Com a discussão entre os carrascos, sobre se devem ou não cumprir a decisão do tribunal, novas indagações surgem sobre o papel institucional do Poder Judiciário e a natureza e finalidade do direito. A metodologia empregada é ficcional, a partir do texto-base original de Lon L. Fuller; o texto original é complementado com uma investigação sobre como teria sido a discussão entre os responsáveis pelo cumprimento da ordem final.
\end{abstract}

Palavras-chave: poder judiciário; hermenêutica jurídica; decisionismo judicial.

Mestre e Doutor em Direito pela Universidade Federal do Rio Grande do Sul (UFRGS). Professor no Curso de Direito da Faculdade Meridional (IMED), em Porto Alegre. Promotor de Justiça no Rio Grande do Sul. Porto Alegre (RS), Brasil. CV Lattes: http://lattes.cnpq.br/4052037774909476. ORCID: https://orcid.org/OOOO-0001-98282664. E-mail: voltairemichel@hotmail.com.

2 Mestre em Relações Internacionais e Doutor em Direito pela Universidade Federal do Rio Grande do Sul (UFRGS). Professor no Curso de Direito da Faculdade Meridional (IMED), em Porto Alegre. Diretor do Campus Porto Alegre da IMED. Porto Alegre (RS), Brasil. CV Lattes: http://lattes.cnpq.br/0342843343545592. ORCID: https://orcid.org/oooo0003-4475-2469. E-mail: marc.deitos@imed.edu.br. 


\section{INTRODUÇÃO}

Roger Whetmore foi assassinado por seus companheiros exploradores de cavernas. Segundo consta dos autos do processo criminal movido contra os sobreviventes, os cinco exploradores viram-se surpreendidos por um acidente, que os impediu de sair da caverna em que se encontravam. Desesperados, e sem perspectiva de socorro, o próprio Roger propôs aos seus colegas de exploração que sorteassem um dos membros do grupo para ser morto e servir de alimento aos demais. Todos concordaram. Instantes antes do sorteio, Roger desistiu de participar, mas era tarde demais. Os demais jogaram os dados por ele e, grande azar, Roger foi sorteado. Roger foi morto por seus colegas e, logo após, o socorro chegou ao interior da caverna.

Os exploradores foram julgados e condenados por homicídio no primeiro grau de jurisdição. Houve recurso, julgado pela Suprema Corte de Newgarth, no ano de 4300. Os juízes, por maioria, deliberaram pela manutenção da sentença condenatória.

Essa é uma breve síntese do artigo publicado por Lon L. Fuller em 1949, intitulado O caso dos exploradores de cavernas. Quase sete décadas após a sua publicação, o caso continua assombrando e instigando professores, alunos e juristas em geral.

Na obra original, vários detalhes instigantes são fornecidos por Lon L. Fuller. No tribunal concebido por ele, cinco juízes apresentaram posições divergentes, que transitavam do mais estrito legalismo, como o voto do Juiz Keen, a uma interpretação mais voluntarista ou jusnaturalista, como a proposta pelo Juiz Foster, ou historicista, como a do Juiz Handy, que sugeria que o julgamento deveria levar em consideração a voz das ruas.

Vários trabalhos foram publicados ao longo das últimas décadas propondo novas interpretações, novos votos para solucionar o caso dos exploradores de cavernas. Em 1980, o professor D’Amato publicou um paper em que sugeria que o Chefe de Estado, em atenção ao pedido de clemência dos exploradores, teria solicitado a ajuda de três professores universitários: Wun, Tieu e Thri. O artigo prossegue com a apresentação dos votos desses três professores. Em 1993, William Eskridge Jr. publicou um estudo introdutório às divergências presentes nos votos originais, seguido de outros sete votos diferentes. Em comemoração aos 50 anos da publicação do artigo, David L. Shapiro publicou, em 1999, um novo estudo 
introdutório ao caso, apresentando outras seis possibilidades diferentes de solução, propostas por diversos autores. No Brasil, em 2010, o professor Dimitri Dimoulis, analisando outra ficção de Lon L. Fuller, propôs um exercício semelhante: partindo de cinco votos originais a respeito da polêmica dos denunciantes invejosos, publicado na obra The Morality of Law, Dimoulis acrescentou outros cinco votos, aumentando a polêmica a respeito do conceito de justiça de transição.

O que se propõe nesse artigo é avançar na sequência de fatos em torno do destino deferido aos exploradores de cavernas; eles já foram julgados, a clemência foi negada pelo Chefe do Executivo e, agora, eles aguardam a execução numa penitenciária de Newgarth. Eles serão executados por três carrascos, chamados Ronaldo, Helmut e Tomás. Os nomes com os quais foram batizados dizem alguma coisa a respeito de suas posições. Talvez seja uma prerrogativa do autor poder provocar os leitores com sugestões e sinais desse tipo.

A estratégia adotada neste ensaio alinha-se com uma tentativa de expor o "direito na literatura", e não apenas "literatura sobre o direito", deixando, nas entrelinhas, a discussão dogmática a respeito dos limites da decisão judicial, e da composição entre texto legal e sentido hermenêutico. Além disso, o formato é, em parte, inspirado em outros trabalhos anteriores que buscaram se afastar na estrutura padrão dos artigos científicos. Tratase de uma discussão que converge com as reflexões a respeito do papel do Poder Judiciário, do Poder Legislativo e, ao fim, ao próprio Poder Executivo, na execução do Direito.

Para manter o estilo originário de Lon L. Fuller, notas bibliográficas ou explicativas foram suprimidas. Ao final, uma lista de referências bibliográficas poderá orientar o leitor para uma busca mais aprofundada.

É provável que os carrascos pareçam esclarecidos demais. Como não há relatos sobre suas formações intelectuais, não foi possível avaliá-las. No entanto, talvez pela peculiaridade da profissão, pela dramaticidade de suas atividades diárias, há a possibilidade de os carrascos preocuparem-se com as questões criminais acima da média do cidadão comum. De qualquer forma, foi a solução mais engenhosa encontrada para recuperar os acontecimentos antecedentes. 
São 6 horas da manhã, do dia 2 de abril de 4300, sexta-feira. As instalações destinadas à execução dos condenados lembram um antigo hospital, com paredes azulejadas em verde e lâmpadas fluorescentes, cuja iluminação é inconstante e fria. Na sala de preparação, estão sentados, ao redor de uma mesa, os três carrascos, aos quais competirá, finalmente, dar fim à vida dos exploradores de cavernas. $\mathrm{O}$ cheiro do local é produto da mistura de café, desinfetantes e de seres humanos. O personagem mais experiente, o carrasco Tomás, é quem toma a palavra inicialmente, e assumirá, nessa fantasia, o papel de retomar os acontecimentos havidos até então.

\section{Carrasco Tomás}

Meus amigos, meus colegas. Há muitos anos trabalhamos juntos nessa infeliz, porém necessária tarefa de dar cabo à vida de nossos compatriotas que, por alguma razão ou outra, por intrínseca maldade ou por influência do meio, praticaram atos detestáveis. Executamos, com os instrumentos a nossa disposição, assaltantes, estupradores, assassinos. Eu mesmo já perdi a conta de quantas vezes cumprimos juntos o nosso dever: buscar os condenados, vesti-los com o macacão apropriado, conduzi-los à sala de execução, preparar o cadafalso, colocar a máscara e a corda em torno ao pescoço e, finalmente, soltar o dispositivo que os sustenta e ainda os mantém presos à vida. Talvez essa rotina tenha embrutecido nossa sensibilidade. Após o cumprimento do nosso dever, voltamos para casa, revemos nossos familiares, brincamos com nossos filhos, até novamente retornar a esse prédio onde diuturnamente cumprimos nosso dever. Lembro-me quando Helmut foi nomeado para trabalhar conosco: ainda jovem, tímido e assustado. Passados alguns meses, já estava adaptado ao peso emocional dessa atividade tão peculiar. Ronaldo e eu começamos na mesma época, enfrentamos o período de formação juntos.

Vocês todos sabem que a execução agendada para hoje é diferente. Os que terão suas vidas ceifadas não são criminosos como nós estamos acostumados a ver. Em geral, nós tomamos conhecimento dos crimes cometidos por nossos executados e, embora não cumpramos nosso dever como vingadores, sabemos que, de uma forma ou outra, merecem a sanção que, quis o destino, seremos os executores. E, pela primeira vez, em vários anos nessa prisão, eu tenho que confessar aos meus colegas: eu estou em dúvida. 
Todos vocês acompanharam o julgamento dos exploradores de cavernas, sobretudo quando o caso se tornou popular ao ser submetido ao Tribunal de Justiça de Newgarth. Os juízes, não obstante seu profundo conhecimento da lei, não chegaram a uma decisão unânime. Todos estão lembrados da polêmica em torno dos votos, não é?

\section{Carrasco Ronaldo}

Claro que estamos lembrados! Os votos foram amplamente divulgados pelos meios de comunicação, e todos os cidadãos, dos mais humildes aos mais poderosos, só falavam desse assunto por semanas. Eu fiquei particularmente impressionado com o voto do Juiz Keen, que simplesmente afirmou que a melhor aplicação da lei seria a condenação dos exploradores nos seus estritos termos, desprezando a argumentação do Juiz Foster.

\section{Carrasco Helmut}

Sim, é verdade. A argumentação do Juiz Foster, no sentido de que os exploradores se encontravam em estado de necessidade, o que lhes permitiria cometer o homicídio, ou, alternativamente, que no interior da caverna os exploradores teriam retrocedido a um estado de natureza, pareceu, pelo menos para mim que não tenho muita instrução, um pouco fantasiosa.

\section{Carrasco Tomás}

E não se esqueçam da argumentação do Juiz Handy, que queria absolver os exploradores de cavernas sob o fundamento de que a população em geral já os havia absolvido. De fato, as manifestações em favor dos exploradores causaram muito alvoroço e pressão sobre o tribunal. E também não há como desprezar a posição dos outros dois juízes, em que um se absteve de votar, enquanto o outro, entregou a decisão ao poder de clemência do Chefe de Estado.

\section{Carrasco Ronaldo}

Se bem me lembro, o Chefe de Estado também ficou em dúvida, e convocou uma comissão de ilustres scholars para orientar sua decisão, os professores Tieu, Thri e Wun. Ainda me recordo da transmissão televisiva dos debates entre esses ilustres professores. O professor Wun, se vocês 
estão recordados, orientou o Chefe de Estado a não conceder a clemência. Segundo ele, direito e moral estão interligados, e a ação dos exploradores de cavernas foi moralmente incorreta. $\mathrm{Na}$ verdade, segundo Wun, os exploradores, quando forçaram a vítima Roger Whetmore a participar do sorteio, constrangeram-no a aderir a um projeto que não lhe interessava, com o propósito exclusivo de aumentarem as suas chances de sobrevivência. Com Roger no sorteio, cada um dos exploradores assassinos elevava, em certo grau, a possibilidade de sobreviver. Ainda me lembro de Wun dizendo que a ação dos exploradores foi moralmente reprovável, e que deveriam pagar o preço pelo homicídio que cometeram egoisticamente.

\section{Carrasco Helmut}

$\mathrm{O}$ voto da professora Tieu foi ainda mais curioso. Assisti com muita atenção. Segundo ela, a maior imoralidade seria o grupo inteiro perecer sob as pedras apenas para a preservação de um indivíduo. Segundo Tieu, era preciso observar aquele pequeno grupo como uma espécie que precisava ser resguardada, a despeito dos interesses e da preservação da vida de um de seus componentes. A vida, de acordo com a professora, consiste na existência continuada de seus membros, e não apenas na vida individual de cada um dos membros. Quer dizer, para proteger e preservar o grupo, valia tudo!

\section{Carrasco Tomás}

Todos recordamos o voto do professor Thri, para quem tanto os exploradores, como o próprio Roger Whetmore, em momentos e circunstâncias diferentes, praticaram atos que seriam moralmente reprováveis. Roger Whetmore, quando se retirou do sorteio, estava, de fato, tentando assegurar a sua própria sobrevivência sem correr nenhum risco, uma vez que, com o sacrifício de outro colega, os demais não lhe poderiam negar um pouco de alimento, sob pena de estarem sacrificando a vida de alguém (de Roger Whetmore) para preservar a propriedade que tinham sobre o corpo do sacrificado. Estariam cometendo, então, o crime de omissão de socorro. Ao mesmo tempo, ao ingressar na caverna e participar dessa atividade coletiva, Roger Whetmore estava assumindo alguns riscos, até mesmo de proteção do grupo, mas se lhe tivesse sido indagado se estaria disposto a sacrificar sua vida para a preservação do grupo, provavelmente 
ele diria não. Então, a associação mútua e temporária na exploração de cavernas não contemplava, e não contempla, a perspectiva de autoimolação em favor do grupo, visto que Roger não estava sendo egoísta quando decidiu não participar do sorteio. Ao se recusar, Roger Whetmore estava apenas ratificando os limites de sua adesão àquela aventura. A posição do professor Thri foi pela comutação das penas para três ou quatro anos de prestação de serviços comunitários num hospital ou instituição similar, onde eles poderiam estar na posição de salvar vidas de pessoas que precisam de ajuda.

Todos lembramos o que aconteceu. O Chefe de Estado, diante da indecisão dos professores, dois pela condenação, outro pela absolvição, tomou a decisão de manter a sentença capital e enviou os exploradores de cavernas à prisão, para a execução da sentença. A execução está marcada para às 9 da manhã. São 8 horas. Temos que começar os preparativos em 30 minutos. Os presos não são nada daquilo a que estamos acostumados. Vamos começar os preparativos?

\section{Carrasco Helmut}

Caro Tomás, assim como tu, algo me incomoda nesse caso. Os juízes, professores, políticos, estão, todos sabemos, numa posição acima da nossa. A nós compete o trabalho sujo, de efetivamente pôr a mão do Estado sobre o corpo de um indivíduo, prendê-lo, enforcá-lo e matá-lo. Talvez seja mais simples à distância, num salão acarpetado e refrigerado, tomar essa decisão. A decisão de condenar à pena capital limita-se a uma palavra digitada numa tela, um debate em que os intelectuais terçam seus argumentos; encerradas as discussões e argumentos, o tribunal apaga suas luzes e os altos funcionários partem para o happy hour, deixando para trás a brutalidade de suas decisões. A nós, aos carrascos, é a quem compete finalmente encerrar o assunto - metafórica e literalmente. O que me assusta nesse caso é que a população em geral é contra a execução. Todos dizem que a execução é uma violência, é um acinte aos direitos humanos dos condenados. Não obstante essa pressão popular, as instituições permaneceram imunes a qualquer pressão ou pedido de clemência. Será que no futuro, essa população, os nossos compatriotas, nossos amigos e vizinhos, não poderão determinar uma modificação nas instituições? Não serão eles, a população em geral, no futuro, novos governantes, professores 
universitários, juízes? E quando essa hora chegar, como avaliarão a nossa conduta mecânica, de simplesmente cumprir a sentença fundada numa votação não unânime?

\section{Carrasco Tomás}

Ora, Helmut, se isso acontecer, diremos que estávamos cumprindo ordens. Aliás, esse é o nosso dever, estaremos no estrito cumprimento do nosso dever legal. A ordem foi dada pela mais alta corte de Newgarth e ratificada pelo nosso Chefe de Estado. Seria possível, no futuro, que tudo se invertesse, e que nós fossemos responsabilizados criminalmente por essa ação? Essa perspectiva me parecer absurda. Se alguém for responsabilizado no futuro por um suposto erro judicial, sejamos todos: tribunais, Chefia de Estado e carrascos. Mas, reitero, essa possibilidade me parece muito remota.

\section{Carrasco Helmut}

Tomás, não sei se isso será suficiente, simplesmente alegar que estávamos cumprindo ordens. O simples fato de estarmos em dúvida, discutindo se devemos ou não cumprir essa sentença, já sinaliza para o fato de que algo deve estar evidente, diante de nós, e que pode colocar a nossa própria vida em risco no futuro. Todos nós estudamos na escola a préhistória da humanidade, fatos ocorridos há três mil anos, quando uma pequena cidade naquela península, então chamada "Europa", foi dividida em duas por um muro, por divergências políticas. Não bastasse a divisão física e a proibição de transitar de um lado para o outro, o que na época não parecia absurda, os governantes de um lado ordenaram aos guardas do muro que, em caso de tentativa de transposição sem autorização, era para disparar. A ordem era perfeitamente legal, e as instituições, amparadas no Direito. E os guardas atiraram quando tiveram a oportunidade. Mas, como todos sabem, aquela situação política não perdurou, o absurdo da ordem tornou-se evidente, os atiradores foram julgados e condenados. E sabem o que os juízes primitivos, no século XX, disseram? Que a eles, aos atiradores, competia avaliar e julgar o que estavam fazendo, que havia normas superiores ao direito positivo, e que os atiradores deveriam ser responsabilizados. O meu receio é que, no futuro, sejamos responsabilizados por essa execução, que hoje chamamos de cumprimento 
de ordem judicial, e que nossos compatriotas poderão qualificar como um homicídio no futuro. E, então, os homicidas seremos nós. E os executados, seremos nós.

\section{Carrasco Tomás}

E, então, assumimos as consequências de desobedecer a ordem do tribunal?

\section{Carrasco Helmut}

Exato. As consequências de desobedecer a uma ordem funcional são menos drásticas que a de cometer um homicídio. Minha posição é a de que não devemos executar os exploradores. Devemos nos recusar. Os juízes, professores, políticos, eles que executem pessoalmente a ordem, e nos processem por essa falta funcional.

\section{Carrasco Tomás}

Sinto dizer que não posso concordar contigo. Parece-me que há algo de errado em não executar a tarefa que nos foi confiada. Em primeiro lugar, veja que somos apenas o fim de uma sequência de instituições, somos apenas mais uma engrenagem do sistema penal. Valorosa ou não a nossa atividade, o certo é que a nós compete a execução das ordens daqueles que estão institucionalmente acima de nós - para o bem e para o mal. Imaginem se a cada julgamento, a cada execução de sentença, nós decidamos que devemos repensar os fundamentos e avaliar se devemos cumprir ou não o que nos é determinado. Isso culminaria em uma paralisia das instituições, ou até mesmo um descrédito. Nós também executamos assassinos e ladrões, pessoas a respeito das quais nunca nos passou pela mente rever seus julgamentos. Mas, será que, nos debruçando agora sobre um caso específico, nós não estaríamos enviando uma mensagem para os futuros criminosos, dizendo que eles talvez possam contar, no futuro, com a nossa indecisão ou misericórdia? Além disso, será que o próprio fato de estarmos discutindo hoje essa decisão não reflete, de certa forma, um certo preconceito de nossa parte com relação aos demais executados? Ora, não é segredo para ninguém que nós estamos prestes a executar pessoas que se parecem bastante com a gente: todos trabalham, têm a mesma cor de pele, pertencem, enfim, à classe média. E nós, como servidores públicos, também 
pertencemos a essa mesma classe. Será que nós não estamos discutindo se devemos executar esses exploradores por solidariedade de classe, e não por alguma dúvida sobre a justiça da decisão original? Não me lembro de termos tergiversado no passado a respeito da execução de outros criminosos.

\section{Carrasco Helmut}

Em minha defesa, digo que só fico sabendo da raça dos executados quando os recebemos aqui no presídio. Pouco me interessa a sua raça.

\section{Carrasco Tomás}

Me vêm à memória um caso antigo, também ocorrido naquela península, então chamada Europa, quando um avião de passageiros (na época voava-se em "charutos" de alumínio movidos à propulsão por incineração de combustível fóssil) foi sequestrado por terroristas (então chamados de terroristas) que ameaçavam lançá-lo sobre um estádio de futebol lotado, em Munique. Consta que um piloto da Força Aérea da Alemanha, desobedecendo a ordens de seus superiores, decidiu, unilateralmente, instantes antes da tragédia, abater o avião em pleno voo, matando todos os seus ocupantes. Também foi julgado e condenado pelo homicídio dos passageiros. Só que, no seu interrogatório, perguntado sobre porque desobedecera às ordens superiores, afirmou que não reconhecia a decisão dos tribunais, tomada meses antes, no sentido de que seria inconstitucional a lei que autorizava os pilotos a abater aviões nessas condições. O piloto, pelo que me lembro, teve a ousadia de dizer que os tribunais haviam errado, e que ele agira certo dessa convicção!

Lembro-me de outro caso curioso, ocorrido por ocasião da execução de Sócrates. Não se surpreendam que um carrasco conheça a história de Sócrates. Até mesmo por deformação profissional, tudo o que tem a ver com execuções acaba atraindo a minha atenção. Quando o filósofo já estava condenado e aguardando a execução, foi visitado por seu aluno Críton, que lhe propôs um plano de fuga. Críton era um homem rico e bem relacionado; colocaria Sócrates num barco e o levaria para longe de Atenas. Sócrates dissuadiu Críton, sob o argumento de que as leis e as instituições de Atenas, até então, havia-os protegido e resguardado. Apenas agora, quando elas lhes eram desfavoráveis, é que surgiria a ideia de desrespeitá-las. Sócrates 
chegou à conclusão de que deveria aceitar o seu destino, quer a decisão tenha sido justa ou injusta.

Será que o desrespeito geral às determinações das instituições, sobretudo as de cúpula, não nos conduziria a uma situação de maior injustiça e instabilidade? Às vezes, sinto que um pouco de injustiça, ou uma injustiça pontual, pode ser suportada por nós, para o bem maior, que é a manutenção das instituições. Não me consta que o Poder Judiciário seja sanguinário, ou que os votos que determinaram a execução dos exploradores tenham sido absurdos ou não fundamentados. De alguma foram ou outra, as instituições falaram e determinaram, ao fim, a morte dos exploradores. Repito: nós não somos, nessa prisão, outra instância recursal a ser provocada pelo impacto emocional. Se nos tornarmos uma nova instância recursal, então teremos que reavaliar o formato das nossas instituições e, talvez, até mesmo melhorar o nosso salário e não escolher somente os casos duvidosos. Sou pela execução da sentença. Vamos preparar a forca.

\section{Carrasco Helmut}

Já que estamos nos posicionando, antecipo que sou por não executar a sentença. Em casos duvidosos como o que se apresenta, deixemos para os magistrados executarem diretamente. Não me sinto confortável em executar pessoas que eu reputo inocentes, apoiadas pela população e absolvidas por, pelo menos, alguns juízes e scholars.

\section{Carrasco Ronaldo}

Caros colegas. Não posso concordar com vocês. Não acho que devemos executar imediatamente a sentença, nem que devemos nos recusar por considerá-la injusta. Tomás, realmente, começamos juntos essa carreira, e enfrentamos juntos todas as dúvidas de consciência que a acompanham. Não me lembro de termos discutido o mérito de uma condenação anteriormente. Discutimos o modo de execução, a duração dos processos, a consequência para as famílias dos condenados e das vítimas, mas nunca questionamos uma decisão judicial. E é aí que me parece que há um obstáculo insolúvel. 


\section{Carrasco Tomás}

Como assim? Entendes que não devemos executar a sentença, mas não a considera injusta? Então por qual razão não a executaríamos?

\section{Carrasco Ronaldo}

Parece-me um rematado absurdo que tenhamos que executar uma decisão judicial de morte com base em maioria de votos de uma corte judicial. Como assim, a maioria decidiu? Será possível, conveniente ou lógico, que não haja uma decisão certa para o caso concreto? Será possível que os juristas mais experientes do país, com dezenas de anos de carreira, sejam capazes de divergir de forma tão acentuada? Esses são os obstáculos que me trazem desconforto. Suponha que a decisão de executar ou não os exploradores de cavernas fosse tomada por votação popular. Tudo indica que venceria o voto pela absolvição, ao menos pelo que vemos nas pesquisas de opinião. No entanto, ainda assim, seria a decisão correta, justa, no caso concreto? As maiorias têm a razão?

\section{Carrasco Helmut}

Entendo a tua preocupação e acho que sei a resposta. Realmente, a maioria pode votar errado, decidir de modo injusto. Pode decidir com base em critérios absolutamente aleatórios e absurdos. Poderiam votar, por exemplo, contra ou a favor, com base na cor da pele, sexo, ou classe social a que pertencem os exploradores de cavernas. Tens razão, o voto da maioria não significa justiça no resultado. A menos que a votação da maioria não se destinasse a decidir qual o resultado final, condenação ou absolvição, mas a escolha de um critério para decidir se haveria condenação ou absolvição...

\section{Carrasco Ronaldo}

Como assim?

\section{Carrasco Helmut}

A maioria decidiria o critério que empregaríamos para condenar ou absolver, porém não a absolvição ou condenação em si. Parece o mesmo, mas não é. Aqui, haveria uma opção por princípios, que talvez impedisse que fatores pessoais, tais como simpatia, raça, afinidade, aparência física, pudessem influenciar na decisão. 


\section{Carrasco Ronaldo}

Entendi. Mas ainda assim, a escolha desse critério pela maioria poderia se revelar equivocado ou injusto. A maioria pode cometer injustiças, quer votando diretamente na absolvição ou condenação, quer votando por um critério de decisão. Na verdade, o que me surpreende é que as instituições simplesmente conseguem conviver com essa indecisão ou flexibilidade. Suponha que amanhã um dos juízes da Suprema Corte de Newgarth se aposente e seja nomeado outro juiz, com posição diferente. A corte mudará, mudarão as decisões, mas o direito mudará? Que direito é esse que depende da composição das cortes? No meu entendimento, na verdade, essa insegurança ocorre apenas pela impossibilidade dos juízes de reconhecerem que há, de fato, um direito, a ser descoberto, independente de sua origem. Com essa expressão "origem", quero dizer, se procede da natureza, ou dos costumes, ou dos valores de uma certa sociedade numa certa época. Acho que tem de haver uma decisão certa, "a" decisão, sob pena de sermos, nós, os executores dos "achismos" dos magistrados. Vejam que a decisão condenatória também foi tomada por maioria, o que não significa que é justa ou correta. Na verdade, eu sei que a norma comporta interpretações divergentes, que não há normas que não sejam interpretáveis. O que me surpreende é que uma corte possa simplesmente desistir de buscar, até o fim, essa decisão correta.

\section{Carrasco Tomás}

$\mathrm{Na}$ condição de membro mais antigo, obrigo-me a resumir a discussão. Eu, como já disse antes, sou pela execução imediata. A nós cabe a execução das decisões, e não a sua revisão. Não compomos um tribunal. O colega Helmut, no entanto, é pela suspensão da execução. Segundo ele, diante da controvérsia a respeito do caso, corremos o risco de sermos responsabilizados no futuro por uma ordem manifestamente ilegal, afrontosa dos direitos humanos dos condenados. Segundo ele, não poderemos, no futuro, dizer que estávamos simplesmente cumprindo ordens, até porque a controvérsia em torno do caso é o que está atrasando essa execução. Por fim, Ronaldo acredita que deve haver uma decisão correta, a ser tomada unanimemente, e reconhecida por toda a comunidade jurídica. 


\section{Carrasco Ronaldo}

O que fazemos então?

\section{Carrasco Tomás - CONCLUSÕES}

Reconhecendo a preponderância da maioria, não devemos cumprir a decisão agora. Vamos devolver a ordem ao tribunal, com uma carta, expondo nossas razões, e aguardar uma decisão final. Vou fazer um rascunho da carta.

Ei-la:

"Senhores Juízes, Senhor Chefe de Estado,

Por ocasião da execução dos exploradores de cavernas, condenados pela Suprema Corte de Newgarth, nós, os carrascos, decidimos suspender os atos preparatórios e devolver a ordem ao juízo, com a solicitação de que seja a decisão novamente debatida até que se chegue a uma sentença unânime a respeito da condenação ou absolvição dos acusados.

Sabemos que com essa ação estamos desobedecendo a ordem que nos foi dada, porém, assumimos as consequências dessa conduta e não nos furtaremos de cumprir nosso dever se a decisão, de fato, refletir o melhor direito e a justiça.

Atenciosamente,

Os Carrascos de Newgarth.”

\section{REFERÊNCIAS}

CAHN, N. et al. The Case of the Speluncean Explorers: Contemporary Proceedings. George Washington Law Review, n. 61, p. 1754-1811, 1993.

COVER, Robert M. Nomos e narração. ANAMORPHOSIS - Revista Internacional de Direito e Literatura, v. 2, n. 2, p. 187-268, julhodezembro 2016. doi: 10.21119/anamps.22.187-268

D'AMATO, A. The Speluncean Explorers - Further proceedings. Stanford Law Review, n. 32, p. 467-485, 1980.

DIMOULIS, D. O caso dos denunciantes invejosos. 6. ed. São Paulo: Revista dos Tribunais, 2010. 95p.

ESKRIDGE, JR., W. The Case of the Speluncean Explorers: TwentiethCentury Statutory Interpretation in a nutshell. George Washington Law Review, n. 61. p. 1731-1753, 1993.

FULLER, L. O caso dos exploradores de cavernas. Porto Alegre: Sergio Antonio Fabris Editor, 1976. 64p. 
NASCIMENTO, João Luiz Rocha do. Das Erínias às Eumênides: como as cadelas vingadoras ainda ladram um passado que não passa. ANAMORPHOSIS - Revista Internacional de Direito e Literatura, v. 3, n. 1, p. 39-72, janeiro-junho 2017. doi: 10.21119/anamps.31.39-72.

PLATÃO. Apologia de Sócrates e Críton. Lisboa: Edições 70, 2007. 87p.

RIBEIRO, Iara Pereira. A exceção e a regra: fragmentos de ema reflexão jurídico-literária. ANAMORPHOSIS - Revista Internacional de Direito e Literatura, v. 1, n. 1, p. 121-138, janeiro-junho 2015. doi: 10.21119/anamps.11.121-138.

SCHIRACH, F. Terror: Ein Theaterstück und eine Rede. Munique: BTB Verlag, 2016. 164p.

SHAPIRO, D. The Case of the Speluncean Explorers: A Fiftieth Anniversary Symposium. Foreword: A cave drawing for the ages. Harvard Law Review, n. 112, p. 1934-1923, 1999.

STRECK, Lenio Luiz. Resposta adequada à Constituição (resposta correta). In: STRECK, Lenio Luiz. Dicionário de hermenêutica: quarenta temas fundamentais da teoria do direito à luz da Crítica Hermenêutica do Direito. Belo Horizonte: Casa do Direito, 2017. p. 258-259.

Idioma original: Português

Recebido: 09/10/17

Aceito: 05/04/18 